\title{
The Reaction of 5-Bromo- and 2-Bromopyrimidine with Organolithium Compounds
}

\author{
SALO GRONOWITZ* and JOHAN RöE \\ Chemical Institute, University of Oslo, Oslo 3, Norway
}

\begin{abstract}
5-Bromopyrimidine undergoes halogen-metal exchange with butyllithium at $-105^{\circ} \mathrm{C}$, yielding 5-pyrimidyllithium from which 5-pyrimidinecarboxylic acid can be obtained in good yield. At higher temperatures several reactions compete with the halogen-metal exchange reaction. Products from the direct addition of butyllithium to the 3,4-azomethine bond of 5-bromopyrimidine and of 5-pyrimidyllithium to the same bond have been obtained. At temperatures over $-80^{\circ} \mathrm{C}$ addition of organolithium compounds to the azomethine bond predominates. Thus, the reaction of 2 -thienyllithium with 5-bromopyrimidine yields 4-(2'-thienyl)-3,4-dihydro-5-bromopyrimidine which can be aromatized to 4-(2'-thienyl)-5-bromopyrimidine. 2-Bromopyrimidine on the other hand did not give any 2-pyrimidinecarboxylic acid on treatment with butyllithium and carbon dioxide even at $-110^{\circ} \mathrm{C}$. Only products from the addition to the 3,4 -azomethine bond could be isolated. Thus addition of 2-thienyllithium to 2-bromopyrimidine yielded 4-(2'-thienyl)-3,4-dihydro-2bromopyrimidine, which was aromatized to 4-(2'-thienyl)-2-bromopyrimidine. Structure determinations were carried out by NMRspectroscopy.
\end{abstract}

$\mathrm{T}$ he halogen-metal interconversion reaction has been shown to be very useful in the thiophene series for the preparation of many different types of mono and disubstituted derivatives. (For review cf. Ref. 1). In the thiophene series this reaction, which is extremely fast even at $-70^{\circ} \mathrm{C}$, is complicated by metalation and rearrangement to the thermodynamically most stable thienyllithium derivatives, if the bromine which is exchanged for lithium is not in the most acidic position. ${ }^{2}$ In the $\pi$-deficient nitrogen-heterocycles the halogen-metal interconversion ${ }^{3}$ has to compete with addition to the formal azomethine linkage. ${ }^{4}$ In the pyridine series by lowering the temperature to $-30^{\circ}$ to $-70^{\circ}$, the addition reaction can be suppressed with 2-bromo-, 3-bromo-, ${ }^{5,6}$ and 4-bromopyridine, ${ }^{7}$ so that the corresponding pyridyllithium derivatives are obtained. Treatment with $\mathrm{CO}_{2}$ or with alde-

* Present address: Institute of Chemistry, University of Lund, Lund, Sweden. 
hydes yields the corresponding acids or carbinols, respectively. However, the yields are mostly below $50 \%$. Although Gilman and Spatz ${ }^{8}$ have suggested several complex side-reactions which could be responsible for the low yield in the halogen-metal interconversion at higher temperature, experimentally these reactions have not been studied or by-products from them described. An example, which is mentioned by Gilman and Spatz ${ }^{8}$ without experimental details, is that the reaction between 3 -bromoquinoline and $p$-dimethylaminophenyllithium yields, after hydrolysis and air-oxidation, 2-p-dimethylaminophenylquinoline, which is interpreted as an example of simultaneous occurrence of halogen-metal interconversion and addition to the azomethine linkage.

Addition to the azomethine bond in pyrimidines has received very little attention. ${ }^{9}$ With 2-aminopyrimidine ${ }^{10}$ and 2-dimethylaminopyrimidine, ${ }^{11}$ only addition to the 3,4-linkage was observed. The yields of substituted pyrimidines were low $(\sim 20 \%)$, partly perhaps due to the fact that no special oxidizing agent was used in order to effect aromatization of the dihydro derivative. Aromatization apparently occurred by elimination of lithium hydride or/and air oxidation during the work-up. Also the addition of organolithium compounds to pyrimidine ${ }^{12}$ and 5-methylpyrimidine ${ }^{13}$ appeared to occur only at the 3,4-bond. In these cases higher yields (up to $50 \%$ ) of 4-substituted pyrimidines were obtained as the original dihydro-derivative was aromatized with potassium permanganate. The dihydro pyrimidines appeared to be more stable than the pyridine analogues, and were not as prone to undergo self-condensation or rapid aerial oxidation. 1,6-Dihydro4-methyl-2,6-diphenylpyrimidine, the addition product from 4-methyl-2phenylpyrimidine, has for instance been isolated in the pure crystalline state. ${ }^{14}$ Only in the reaction of phenyllithium with 4-methylpyrimidine did addition to both the 3,4- and 2,3-bond occur, since it is claimed that a mixture of 4-methyl-6-phenylpyrimidine and 4-methyl-2-phenylpyrimidine is obtained. ${ }^{14}$

The addition to the azomethine linkage in pyrimidines appears to be more rapid than in the corresponding pyridines. Thus pyrimidine adds phenylmagnesium bromide at room temperature, ${ }^{12}$ while a higher temperature is necessary in order to obtain addition to pyridine. ${ }^{15}$ Organolithium compounds add smoothly to pyrimidine even at $-30^{\circ} \mathrm{C} .12$ The greater reactivity of the azomethine linkage in pyrimidines than in pyridines is also illustrated by the fact that 2- and 4-picoline are easily metalated in the lateral acidic methyl group, while the corresponding experiment with 2-methylpyrimidine and 4-methylpyrimidine led only to addition. ${ }^{14}$ Only with $2,4,6$-trimethylpyrimidine lateral metalation was obtained. ${ }^{14}$ These results are hardly due to lesser acidity of the methyl groups in 2- and 4-methylpyrimidine, as the pyrimidyl group is a stronger electron attractor than the pyridyl group.

Only very few examples of successful halogen-metal interconversions with substituted halopyrimidines are described in the literature. From the reaction of 2,4-diethoxy-6-bromopyrimidine and butyllithium at $-80^{\circ}$, followed by carbonation, 2,4-diethoxy-6-pyrimidinecarboxylic acid was obtained in about $50 \%$ yield. 2,4-Diethoxy-6-pyrimidyllithium is claimed to be very unstable even at $-80^{\circ} \mathrm{C}^{16}$ Halogen-metal interconversion has 
also been observed at $-65^{\circ}$ between 5-bromo-2,4-dimethoxypyrimidine and butyllithium. ${ }^{17}$ In this case 2,4-dimethoxy-5-pyrimidine carboxylic acid is obtained in $55-75 \%$ yield. Recently boronic acids obtained through the reaction of 2,4-dimethoxy-5-pyrimidyllithium with trimethyl borate have been described. ${ }^{18}$ Upon alkylation of the lithium intermediate with methyl or ethyl iodide, less than $30 \%$ of alkylated product is obtained. ${ }^{17}$

Both Langley ${ }^{16}$ and Ulbricht ${ }^{17}$ suggest that the instability of the pyrimidyllithium derivatives is due to self-condensations through addition to the azomethine linkage, but do not describe any products from such reactions.

In order to obtain information about halogen-metal interconversion and addition in bromopyrimidines, we have studied the reaction between 5bromopyrimidine and organolithium compounds in some detail. We found that highest yield $(68 \%)$ of 5 -pyrimidinecarboxylic acid was obtained when working at $-105^{\circ}$ to $-110^{\circ} \mathrm{C}$ in a mixture of ether and tetrahydrofuran, using a $50 \%$ excess of butyllithium and a reaction time of about $20 \mathrm{~min}$.* Shorter reaction times gave lower yields of acid, and unchanged 5-bromopyrimidine was recovered. When working at $-80^{\circ} \mathrm{C}$ in ether solution, only small amounts of the 5-pyrimidinecarboxylic acid were obtained, in low yield in addition to other compounds. One was isolated from the acidic aqueous phase and analysed as $\mathrm{C}_{8} \mathrm{H}_{8} \mathrm{BrClN}_{4}$, and was shown to be the hydrochloride of 4-(5-pyrimidyl)-3,4-dihydro-5-bromopyrimidine (I). This was evident from its IR-spectrum which showed strong NH-stretching bands at about $2850 \mathrm{~cm}^{-1}$. It showed also sharp bands at $1670 \mathrm{~cm}^{-1}$ and $1625 \mathrm{~cm}^{-1}$, which we have observed in several other 3,4-dihydropyrimidines (cf. below) and which most probably are due to the $\mathrm{C}=\mathrm{C}$ and $\mathrm{C}=\mathrm{N}$ stretching frequencies. In non-tautomeric pyrimidines, absorption due to interaction of the ring double bonds is observed between 1580-1520 $\mathrm{cm}^{-1}{ }^{21}$ Another compound, m.p. $119-120^{\circ}$, isolated in very low yield from the ether extracts was shown to be 4-(5'-pyrimidyl)-5-bromopyrimidine (II). In its IR-spectrum the peaks characteristic of the dihydro compound were absent, and it showed only aromatic absorption at $1550 \mathrm{~cm}^{-1}$. Its IR-spectrum was also different from that of the free base obtained from I by treatment with alkali. Its NMRspectrum showed absorption between $0.72-0.94 \tau$, which is in the region expected for 2- and 4-hydrogens in pyrimidines. II is most probably formed by aromatization of the primary addition product of 5-pyrimidyllithium to the 3,4-linkage of 5-bromopyrimidine. The yield of II could be increased by adding half an equivalent of butyllithium to 5 -bromopyrimidine at $-80^{\circ} \mathrm{C}$, followed by hydrolysis and aromatization of the reaction product.

Carrying out the reaction at a still higher temperature led only to a syrupy product from which none of the above-mentioned products could be isolated, but which clearly was a 3,4-dihydropyrimidine as it showed the characteristic absorption bands at $2850 \mathrm{~cm}^{-1}, 1665 \mathrm{~cm}^{-1}$, and $1620 \mathrm{~cm}^{-1}$.

\footnotetext{
* This is the most convenient route to 5-pyrimidinecarboxylic acid, as attempts to prepare the acid through acid or basic hydrolysis of 5-cyanopyridimine ${ }^{10}$ only led to impure acid in low yield. Also attempts to prepare the methyl ester directly through the iminoether hydrobromide ${ }^{20}$ were not successful, as a mixture of 5-pyrimidinecarboxylic acid amide (26\%) and methyl 5-pyrimidinecarboxylate (31 \%) was obtained, which could easily be separated due to the insolubility of the amide in hot petroleum ether.
}

Acta Chem. Scand. 19 (1965) No. 7 
<smiles>Brc1cn2[nH]cnc2n1</smiles>

I<smiles></smiles>

II

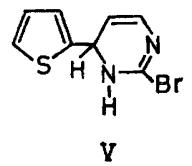<smiles></smiles>

III<smiles>Brc1nccc(-c2cccs2)n1</smiles>

YI

Aromatization of this product with potassium permanganate yielded mainly impure 4-butyl-5-bromopyrimidine as was evident from the NMRand IR-spectrum of the product.

No products could be detected indicating benzyne-type intermediates in the reaction of 5-bromopyrimidine with butyllithium.

That addition to the azomethine linkage at higher temperature was more rapid than halogen-metal interconversion was also evident from the reaction of 2 -thienyllithium with 5-bromopyrimidine at $-30^{\circ}$. The syrupy product was not purified, but its NMR-spectrum indicated that it consisted mainly of 4-(2'-thienyl)-3,4-dihydro-5-bromopyrimidine (III). After aromatization of the product with potassium permanganate, 5-bromo-4-(2'-thienyl)-pyrimidine (IV) was obtained in good yield. The structure of the compound was clearly proven by its NMR-spectrum in dimethyl sulphoxide, which showed five peaks of equal intensities (Fig. 1). The peaks at $0.88 \tau$ and $0.94 \tau$ showing no resolved splitting were assigned to hydrogen 2 and hydrogen 6 of the pyrimidine ring. It is known that $J_{26}$ is very small $(<0.6 \mathrm{c} / \mathrm{s})$ in pyrimidines. ${ }^{19}$ The other three bands were quartets. The band at $1.56 \tau$ showed splittings of 1.2 and $3.9 \mathrm{c} / \mathrm{s}$ and was thus assigned to hydrogen 3 of the thiophene ring. The band at $2.00 \tau$ showed splittings of $1.2 \mathrm{c} / \mathrm{s}$ and $5.2 \mathrm{c} / \mathrm{s}$ and was thus assigned to hydrogen 5 of the thiophene ring. Finally the band at $2.70 \tau$ showed

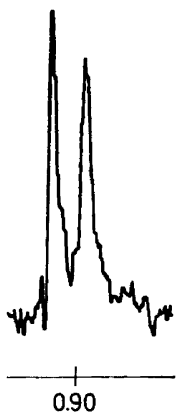<smiles>Brc1cncnc1-c1ccsc1Br</smiles>
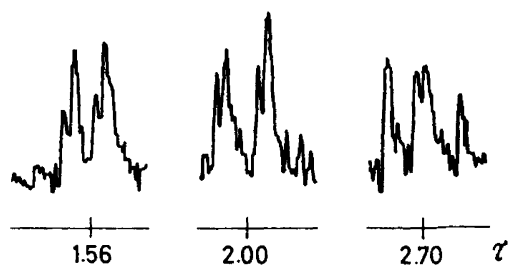

Fig. 1. NMR-spectrum at $60 \mathrm{Mc} / \mathrm{s}$ of 4-(2'-thienyl)-5-bromopyrimidine in dimethyl sulphoxide solution.

Acta Chem. Scand. 19 (1965) No. 7 
splittings of 3.8 and $5.2 \mathrm{c} / \mathrm{s}$ and was therefore assigned to hydrogen 4 of the thiophene ring. These assignments are based on the well-known magnitudes of thiophene ring coupling constants. ${ }^{22}$

From the products obtained the following picture of the reaction of 5bromopyrimidine with butyllithium arises. At extremely low temperatures halogen-metal interconversion predominates. At somewhat higher temperatures the addition of the primarily formed 5-pyrimidyllithium to the azomethine linkage of 5-bromopyrimidine, and probably also addition of butyllithium to 5-bromopyrimidine, competes with the halogen-metal interconversion. From $-30^{\circ} \mathrm{C}$ direct addition of the metal-organic reagent to the 3,4 -bond is the predominate reaction. The apparently quite different activation energies of the halogen-metal interconversion reaction and the addition reaction, make it thus possible to utilize the reactivity of 5-bromopyrimidine with butyllithium in quite different ways.

We have also studied the reaction between 2-bromopyrimidine and butyllithium to some extent. However, even when working at $-105^{\circ} \mathrm{C}$, we were not able to isolate any 2-pyrimidinecarboxylic acid. It appears that in this case the addition reaction even at $-100^{\circ} \mathrm{C}$ is more rapid than the halogenmetal interconversion. This is perhaps not so unexpected, as the halogen in the 2-position, which is very reactive toward nucleophilic substitution, easily leaving as the halide anion, has to leave without its binding electrons in the halogen-metal interconversion. A syrupy addition product was isolated, which on attempted aromatization yielded a red polymeric product, which was not further investigated. The addition of 2-thienyllithium to 2-bromopyrimidine on the other hand gave a crystalline product, m.p. $108-110^{\circ}$, which IR- and NMR spectroscopy clearly proved to be 4-(2'-thienyl)-3,4-dihydro2-bromopyrimidine (V). Its NMR-spectrum in DMSO showed a broad band at $2.06 \tau$ assigned to the NH, and a quartet at $2.58 \tau$ with splittings characteristic for the 3 -hydrogen of the thiophene ring. The resonances of the 4and 5-thiophenic hydrogens coincided in the band at $3.03 \tau$. The three remaining resonances of the dihydro pyrimidine ring occurred at $3.83 \tau$ as a doublet with a splitting of $6.9 \mathrm{c} / \mathrm{s}$, at $4.45 \tau$ as a doublet with a splitting of $3.2 \mathrm{c} / \mathrm{s}$, and at $5.12 \tau$ as a quartet with splittings of $3.2 \mathrm{c} / \mathrm{s}$ and $6.9 \mathrm{c} / \mathrm{s}$. From our knowledge of the magnitudes of coupling constants in unsaturated heterocyclic compounds (cf. for instance the coupling constants in 3-thiolene-2ones) ${ }^{23}$ it can safely be assumed that the larger coupling is between the hydrogens at the double bond. This identified the resonance at $3.83 \tau$ as that of hydrogen 6 , that at $4.45 \tau$ as that of hydrogen 4 , and that at $5.12 \tau$ as that of hydrogen 5 of the dihydropyrimidine ring. The position of the NH resonance was very much dependent on the purity of the compound and the solvent, and in some recordings couplings to the NH hydrogen were observed in the 6-hydrogen band.

Aromatization of $\mathrm{V}$ to 4-(2'-thienyl)-2-bromopyrimidine (VI) could be carried out in good yield with potassium permanganate. Its NMR-spectrum (Fig. 2) clearly proved the structure. It showed a doublet at $1.35 \tau$ with a splitting of $5.5 \mathrm{c} / \mathrm{s}$ assigned to hydrogen 6 of the pyrimidine ring. A quartet at $1.88 \tau$ with splittings of $1.2 \mathrm{c} / \mathrm{s}$ and $3.8 \mathrm{c} / \mathrm{s}$ is assigned to hydrogen 3 of the thiophene ring. The quartet at $2.08 \tau$ with splittings of $1.2 \mathrm{c} / \mathrm{s}$ and $5.5 \mathrm{c} / \mathrm{s}$ is

Acta Chem. Scand. 19 (1965) No. 7 

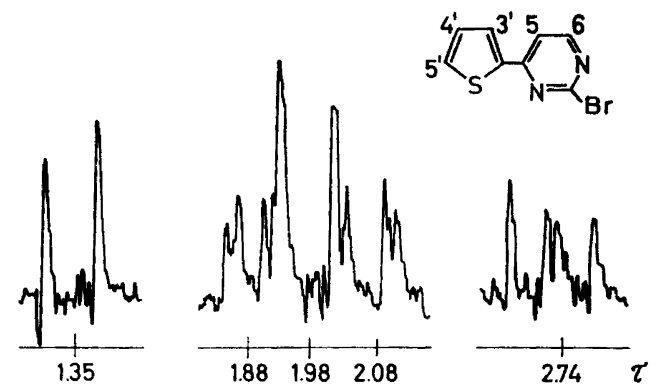

Fig. 2. NMR-spectrum at $60 \mathrm{Mc} / \mathrm{s}$ of 4-(2'-thienyl)-2-bromopyrimidine in dimethyl sulphoxide solution.

assigned to hydrogen 5 of the thiophene ring. These quartets are partly overlapped by the doublet at $1.98 \tau$ from hydrogen 5 of the pyrimidine ring. Finally the quartet at $2.74 \tau$ with splittings of $3.6 \mathrm{c} / \mathrm{s}$ and $4.9 \mathrm{c} / \mathrm{s}$ belongs to the thiophenic 4-hydrogen.

The chemical shifts of the thiophenic hydrogens in IV and VI compared with those of the corresponding dihydro compounds, illustrate the strong electron-attracting power of the pyrimidyl ring as a substituent. The resonances of the 3- and 5-hydrogens of the thiophene ring occur at low field. For the 3-hydrogen this is partly due to the neighbour anisotropy effect (ring-current effect) of the pyrimidine ring, which, however, cannot be of large importance in determining the shifts of the 5-hydrogen, which thus is mainly determined by the electron density at this hydrogen. The 5-hydrogen resonance of 2-nitrothiophene occurs at $1.91 \tau$ in the same solvent, indicating that the electron-attracting properties of 5-bromo-4-pyrimidyl and 2-bromo4-pyrimidyl groups are comparable with those of the nitro group. The same effect has also been observed for the unsubstituted pyrimidine ring of 4( 2 '-thienyl)-pyrimidine. For a discussion of the factors determining the chemical shifts in thiophenes $c f$. Ref. 24. In the dihydro derivatives, the lowest thiophenic hydrogen resonance occurs at $2.58 \tau$ in $V$ and at $2.56 \tau$ in III. These are identified as the resonance of hydrogen 3 by its couplings. In the former compound as mentioned before, the 4- and 5-hydrogen resonances occur at 3.0 $\tau$, while those of the latter compound cannot be identified with certainty due to overlap with the pyrimidinic hydrogens, but most probably can be ascribed to bands in the 3.0 $\tau$ region. As the resonances of the $\alpha$ - and $\beta$-hydrogens of thiophene occur at $2.45 \tau$ and $2.86 \tau$ in DMSO, it is evident that dihydropyrimidyl only has a weak substituent effect on the chemical shifts of the thiophenic hydrogens.

\section{EXPERIMENTAL}

5-Bromopyrimidine and butyllithium at $-110^{\circ} \mathrm{C}$. To a well-stirred solution of $8.0 \mathrm{~g}$ $(0.05 \mathrm{~mole})$ of 5 -bromopyrimidine ${ }^{25}$ in $500 \mathrm{ml}$ of a $1: 1$ mixture of ether and tetrahydrofuran, cooled to -105 to $-110^{\circ} \mathrm{C}$ (alcohol and liquid nitrogen), was added under nitrogen during $10 \mathrm{~min} 70 \mathrm{ml}$ of $1.1 \mathrm{~N}$ butyllithium cooled to $-110^{\circ} \mathrm{C}$, and the mixture was stirred for additional $10 \mathrm{~min}$ at that temperature. The yellow solution was poured 
onto solid carbon dioxide covered with ether. The mixture was allowed to warm to room temperature, and was then hydrolysed with water. The ether phase was extracted 6 times with small portions of water and then with $1 \mathrm{~N}$ sodium hydroxide solution. The combined aqueous solutions were acidified with $6 \mathrm{~N}$ hydrochloric acid to $\mathrm{pH} 2-3$, precipitating $4.3 \mathrm{~g}(68 \%)$ of 5-pyrimidinecarboxylic acid, m.p. $267-270^{\circ}$, which had the same IR-spectrum as an authentic sample prepared through decarboxylation of 4,5-pyrimidinedicarboxylic acid. ${ }^{26}$

5-Bromopyrimidine and butyllithium at $-80^{\circ} \mathrm{C} .8 .0 \mathrm{~g}(0.05 \mathrm{~mole})$ of 5 -bromopyridine in $250 \mathrm{ml}$ of ether was cooled to $-80^{\circ} \mathrm{C}$, and $65 \mathrm{ml}$ of $0.92 \mathrm{~N}$ ethereal butyllithium at the same temperature was added during $1 \frac{1}{2} \mathrm{~min}$ and the mixture stirred for additional $3 \mathrm{~min}$ before carbonation. The same work-up as described above yielded only traces of 5-pyrimidinecarboxylic acid. Slow evaporation of the acidified aqueous solution yielded $0.7 \mathrm{~g}$ of 4-(5-pyrimidyl)-3,4-dihydro-5-bromopyrimidine hydrochloride, m.p. 208-209 ${ }^{\circ}$, after recrystallization from alcohol. (Found: $\mathrm{C} 34.86 ; \mathrm{H} \mathrm{3.12}$; $\mathrm{N} 20.30$. Calc. for $\mathrm{C}_{8} \mathrm{H}_{8} \mathrm{BrClN}_{4}$ : $\mathrm{C} \mathrm{34.81;} \mathrm{H} \mathrm{2.92;} \mathrm{N} \mathrm{20.33}$.) After evaporation of the ether, small amounts of a crystalline compound were filtered off and recrystallized from alcohol, yielding $0.030 \mathrm{~g}$ of 4-(5-pyrimidyl)-5-bromopyrimidine, m.p. 119-120 . (Found: C 40.76; H 2.27; $\mathrm{N}$ 23.68; $\mathrm{Br} 33.36$. Calc. for $\mathrm{C}_{8} \mathrm{H}_{5} \mathrm{BrN}_{4}$ : $\mathrm{C} 40.52 ; \mathrm{H} 2.12 ; \mathrm{N} 23.64 ; \mathrm{Br}$. 33.79.)

4-(5'-Pyrimidyl)-5-bromopyrimidine. $8.0 \mathrm{~g}(0.050 \mathrm{~mole})$ of 5 -bromopyrimidine in $250 \mathrm{ml}$ of anhydrous ether was cooled to $-80^{\circ} \mathrm{C}$, and $22 \mathrm{ml}$ of $1.19 \mathrm{~N}(0.026 \mathrm{~mole})$ ethereal butyllithium was added with stirring and under nitrogen during $12 \mathrm{~min}$. After additional stirring for 10 min the mixture was poured onto $100 \mathrm{ml}$ of water. The organic layer was separated and the alkaline water-phase extracted ten times with ether. The combined ether-phases were dried over sodium sulphate and the ether removed in vacuo. The partly crystalline residue was dissolved in 11 of acetone. This solution was placed in a flask fitted with a Soxhlet extractor containing a mixture of $3.5 \mathrm{~g} \mathrm{(0.022} \mathrm{mole)} \mathrm{of} \mathrm{finely}$ powdered potassium permanganate and glass wool, and the potassium permanganate continuously extracted. The manganese dioxide was filtered off and washed with acetone. The acetone solution was dried with sodium sulphate and the acetone distilled off, yielding $1.25 \mathrm{~g}(19 \%)$ of 4 -(5'-pyrimidyl)-5-bromopyrimidine, after recrystallization from ethanol, m.p. $119-120^{\circ}$, and having the same IR-spectrum as the sample described above.

5-Bromopyrimidine and butyllithium at $+20^{\circ} \mathrm{C}$. To a well-stirred solution of $8.0 \mathrm{~g}$ $(0.05$ mole) of 5-bromopyrimidine in $250 \mathrm{ml}$ of dry ether was added rapidly $78 \mathrm{ml}$ of $0.97 \mathrm{~N}$ butyllithium, and the mixture was stirred for $5 \mathrm{~min}$. The mixture was hydrolysed through the addition of $50 \mathrm{ml}$ of ice-cold water, the ether phase was separated and the alkaline water-phase extracted seven times with ether. The combined ether phases were dried and the ether distilled off, leaving $6.3 \mathrm{~g}(58 \%)$ of a syrupy oil consisting mainly of 4-butyl-3,4-dihydro-5-bromopyrimidine, which is evident from its $\mathrm{NH}$ stretching at $2900 \mathrm{~cm}^{-1}$ and the $\mathrm{C}=\mathrm{N}$ and $\mathrm{C}=\mathrm{C}$ stretchings at $1665 \mathrm{~cm}^{-1}, 1618 \mathrm{~cm}^{-1} .2 .9 \mathrm{~g}^{-1}$ $(0.020 \mathrm{~mole})$ of the dihydro compound in $1 \mathrm{l}$ of acetone was treated with $2.1 \mathrm{~g}(0.013$ mole) of finely-powdered potassium permanganate in the same way as described above, yielding $1.4 \mathrm{~g}$ of impure 4 -butyl-5-bromopyrimidine, b.p. $92-96^{\circ} / 8 \mathrm{~mm} \mathrm{Hg}$. NMR: (DMSO) $\tau_{2} 0.90 \mathrm{ppm} ; \tau_{6} 1.07 \mathrm{ppm}$.

4-(2'-Thienyl)-5-bromopyrimidine. To a solution of 2-thienyllithium, prepared from $4.2 \mathrm{~g}(0.050 \mathrm{~mole})$ of thiophene in $50 \mathrm{ml}$ of ether and $55 \mathrm{ml}$ of $0.97 \mathrm{~N}$ butyllithium and cooled to $-30^{\circ} \mathrm{C}$, was added with stirring during $12 \mathrm{~min}$ a solution of $8.0 \mathrm{~g}(0.050 \mathrm{~mole})$ of 5-bromopyrimidine in $230 \mathrm{ml}$ of ether. The temperature was allowed to rise to about $0^{\circ} \mathrm{C}$ and the reaction mixture hydrolysed with $50 \mathrm{ml}$ of ice-cold water. The water phase was extracted several times with ether and the combined ether phases dried over magnesium sulphate. The ether was distilled off leaving $11 \mathrm{~g}(90 \%)$ of crude 4 -( $2^{\prime}$-thienyl)3,4-dihydro-5-bromopyrimidine. IR (liquid): $\mathrm{NH} 290 \mathrm{~cm}^{-1} ; \mathrm{C}=\mathrm{C}, \mathrm{C}=\mathrm{N} 1665 \mathrm{~cm}^{-1}$, $1618 \mathrm{~cm}^{-1}$. NMR (DMSO): $2.56 \tau$ (quartet, $J 1.9 \mathrm{c} / \mathrm{s}, 3.9 \mathrm{c} / \mathrm{s}$ ); $2.85 \tau ; 3.00 \tau ; 3.34 \tau ; 4.35 \tau$, (2-hydrogens); $4.48 \tau$. $10.6 \mathrm{~g}(0.044 \mathrm{~mole})$ of the crude dihydropyrimidine in $1.31 \mathrm{of}$ acetone was treated with $4.7 \mathrm{~g}(0.030 \mathrm{~mole})$ of potassium permanganate in the same way as described above, yielding $4.3 \mathrm{~g}(41 \%)$ of 4-(2'-thienyl)-5-bromopyrimidine, b.p. $150-160^{\circ} / 8 \mathrm{~mm} \mathrm{Hg}$, which crystallized from acetone in fine needles, m.p. 208-210 $\mathrm{C}$ The analytical sample was sublimed in vacuo. (Found: $\mathrm{C}$ 39.94; H 2.49; N 11.09; $\mathrm{S} 12.90$; Br 33.06. Calc. for $\mathrm{C}_{8} \mathrm{H}_{5} \mathrm{BrN}_{2} \mathrm{~S}$ : C 39.85; $\mathrm{H}$ 2.09; $\mathrm{N} 11.20 ; \mathrm{S} 13.29 ; \mathrm{Br} 33.15$.) $\mathrm{NMR}: \tau_{2}$ $0.88 ; \tau_{6} 0.94 ; \tau_{3} 1.56 ; \tau_{5} 2.00 ; \tau_{4} 2.70 ; J_{46}^{\prime} 5.0 \mathrm{c} / \mathrm{s} ; J_{9}^{\prime 4} 3.8 \mathrm{c} / \mathrm{s} ; J_{8}^{\prime 6} 1.1 \mathrm{c} / \mathrm{s}$.

Acta Chem. Scand. 19 (1965) No. 7 
4-(2'-Thienyl)-3,4-dihydro-2-bromopyrimidine. This was prepared in the same way as described above, using $4.2 \mathrm{~g}(0.050 \mathrm{~mole})$ of thiophene, $55 \mathrm{ml}$ of $0.97 \mathrm{~N}$ butyllithium and $8.0 \mathrm{~g}(0.050 \mathrm{~mole})$ of 2-bromopyrimidine ${ }^{27}$, yielding $7.7 \mathrm{~g}(64 \%)$ of 4 -(2'-thienyl)3,4-dihydro-2-bromopyrimidine, m.p. $108-110^{\circ} \mathrm{C}$, after recrystallization from ether. (Found: C 39.58; $\mathrm{H} \mathrm{3.11;} \mathrm{N}$ 11.57; $\mathrm{S}$ 13.13; Br 32.04. Calc. for $\mathrm{C}_{8} \mathrm{H}_{7} \mathrm{BrN}_{2} \mathrm{~S}$ : C 39.52; $\mathrm{H} 2.89$; N 11.52; S 13.19; Br 32.87.) NMR (DMSO): $2.06 \tau ; 2.58 \tau$ (quartet); $3.03 \tau$ (two hydrogens); $3.83 \tau(J 6.9 \mathrm{c} / \mathrm{s}) ; 4.45 \tau(J 3.2 \mathrm{c} / \mathrm{s}) ; 5.12 \tau(J 6.9 \mathrm{c} / \mathrm{s}, 3.2 \mathrm{c} / \mathrm{s})$.

4-(2'-Thienyl)-2-bromopyrimidine. $7.3 \mathrm{~g}(0.030 \mathrm{~mole})$ of the dihydropyrimidine was treated with $3.5 \mathrm{~g} \quad(0.022$ mole) of potassium permanganate yielding $5.3 \mathrm{~g}(74 \%)$ of 4-(2'-thienyl)-2-bromopyrimidine, m.p. 122-125 after sublimation at $0.01 \mathrm{~mm} \mathrm{Hg}$. (Found: $\mathrm{C} 40.50 ; \mathrm{H} 2.64 ; \mathrm{N} 11.99 ; \mathrm{S} 13.08 ; \mathrm{Br}$ 32.08. Calc. for $\mathrm{C}_{8} \mathrm{H}_{5} \mathrm{BrN}_{2} \mathrm{~S}$ : $\mathrm{C}$ 39.85; $\mathrm{H} 2.09 ; \mathrm{N} 11.20 ; \mathrm{S} \mathrm{13.29;} \mathrm{Br} 33.15.) \mathrm{NMR}$ (Acetone): $\tau_{8} 1.35 ; \tau_{3} 1.88 ; \tau_{5} 1.98 ; \tau_{5} 2.08$; $\tau_{4} 2.74 ; J_{s^{\prime}} 5.5 \mathrm{c} / \mathrm{s} ; J_{4^{\prime}} 4.8 \mathrm{c} / \mathrm{s} ; J_{\mathrm{s}^{\prime}} 3.8 \mathrm{c} / \mathrm{s} ; J_{a^{\prime}} 1.2 \mathrm{c} / \mathrm{s}$.

The NMR-spectra were obtained on a Varian Associates DP-60 model V-4302 NMR. spectrometer operating at $60 \mathrm{Mc} / \mathrm{s}$ and a 12" Varian magnet V-4012 A, equipped with integrator and back-ground stabilizer. The magnet sweep was calibrated using the modulation side-band technique. The variable frequency was obtained from a Hewlett Packard Wide range oscillator model $200 \mathrm{CD}$ and measured with a Beckman, Model 6146 Universal EPUT timer. The IR-spectra were recorded on a Beckman IR-5A infrared spectrophotometer.

Acknowledgments. The authors are indebted to Fil.lic. Anna-Britta Hörnfeldt and Miss Merete Lange for the NMR-spectra. The elementary analyses were carried out by Ilse Beetz, Mikroanalytisches Laboratorium, Kronach.

\section{REFERENCES}

1. Gronowitz, S. In Katritzky, A.R., Ed., Advances in Heterocyclic Chemistry, New York 1963, p. 1 .

2. Moses, P. and Gronowitz, S. Arkiv Kemi 18 (1961) 119.

3. Klingsberg, E. Pyridine and its Derivatives, New York 1961, Part 2, p. $358 \mathrm{H}$ and p. $422 \mathrm{H}$.

4. Klingsberg, E. Pyridine and its Derivatives, New York 1961, Part 2, pp. 171-172.

5. Wibaut, J.P., De Jonge, A.P., Van der Voort, H.G.P. and Otto, P.Ph.H.L. Rec. Trav. Chim. 70 (1951) 1054.

6. Gilman, H. and Spatz, S.M. J. Am. Chem. Soc. 62 (1940) 446.

7. Wibaut, J.P. and Herringa, L.G. Rec. Trav. Chim. 74 (1955) 1003.

8. Gilman, H. and Spatz, S.M. J. Org. Chem. 16 (1951) 1485.

9. Brown, D.J. The Pyrimidines, New York 1962, pp. 118, 123.

10. Detweiler, W.K. and Amstutz, E.D. J. Am. Chem. Soc. 73 (1951) 5451.

11. Overberger, C.G. and Kogon, I.C. J. Am. Chem. Soc. 76 (1954) 1065.

12. Bredereck, H., Gomper, R. and Herlinger, H. Chem. Ber. 91 (1958) 2832.

13. Bredereck, H., Herlinger, H. and Renner, J. Chem. Ber. 93 (1960) 230.

14. Heyes, T.D. and Roberts, J. C. J. Chem. Soc. 1951328.

15. Bergström, F.W. and McAllister, S.H. J. Am. Chem. Soc. 52 (1930) 2845.

16. Langley, B.W. J. Am. Chem. Soc. 78 (1956) 2136.

17. Ulbricht, T.L.V. Tetrahedron 6 (1959) 225.

18. Liao, T.K., Podrebarac, E.G. and Cheng, C.C. J. Am. Chem. Soc. 86 (1964) 1869.

19. Gronowitz, S., Norrman, B., Gestblom, B., Mathiasson, B. and Hoffman, L.A. Arkiv Kemi 22 (1964) 65.

20. Morgan, D.J. Chem. Ind. (London) 1959854.

21. Short, L.N. and Thompson, H.W. J. Chem. Soc. 1952168.

22. Hoffman, R.A. and Gronowitz, S. Arkiv Kemi. 16 (1960) 563.

23. Hörnfeldt, A-B. and Gronowitz, S. Arkiv Kemi 75 (1963) 239.

24. Gronowitz, S. and Hoffman, R.A. Arkiv Kemi 16 (1960) 539.

25. Bredereck, B., Effenberger, F. and Schweizer, E.H. Chem. Ber. 95 (1962) 803.

26. Gabriel, S. and Colman, J. Ber. 37 (1904) 3643.

27. Bly, D.D. and Mellon, M.G. J. Org. Chem. 27 (1962) 2945.

Received June 11, 1965. 